\title{
Análise das práticas de reuso de água residual: estudo de casos em lavanderias industriais
}

\author{
Analysis of residual water reuse practices: case study in industrial laundry
}

Mariane Cásseres de Souza1 , Andrea Vargas 2 , Gislaine Saueressig 3, Juliane Luchese ${ }^{4}$,

Jéssica Mariella Bauer ${ }^{5}$ e Cláudia Viviane Viegas ${ }^{2}$

1,2,3,4,5 Mestranda/o em Engenharia de Produção e Sistemas pelo PPGEPS UNISINOS

${ }^{6}$ Professora e pesquisadora do PPGEPS UNISINOS

\begin{abstract}
Resumo
Água é um insumo de uso abundante em processos de lavanderias industriais. O reuso da água em Estação de Tratamento de Efluente reduz custos e traz benefícios ambientais, ou seja, é um fator de ecoeficiência. O objetivo deste estudo é analisar as práticas de reuso de água em lavanderias industriais em suas Estações de Tratamento de Efluentes. Para tanto foram estudadas duas empresas do ramo de lavanderias industriais, de médio porte, localizadas na região Sul do Brasil. O método de pesquisa foi o estudo de caso múltiplo. Os resultados obtidos identificaram a diminuição da carga poluidora com o processo de reuso da água, com consequente redução de custos. Verificou-se a aplicação de tecnologias e substâncias utilizadas sem prejudicar o meio ambiente com a utilização de lavagem úmida e a seco. A partir dos resultados, propõe-se uma visão das melhores práticas encontradas no reuso da água associada aos benefícios da gestão da produção mais limpa em termos de ecoeficiência.
\end{abstract}

Palavras-chave: Reuso da Água. Lavanderia Industrial. Ecoeficiência.

\begin{abstract}
Water is an abundantly used input in industrial laundry processes. The reuse of water in effluent treatment plant reduces costs and brings environmental benefits, that is, an eco-efficiency factor. This study aims to analyze the practices of water reuse in industrial laundries on its effluent treatment plants. In this regard it was studied two medium-sized companies in the field of industrial laundries located in southern Brazil. The research method used was multiple case study. The results show the decrease in the polluting load with the water recycling process with consequent cost reduction. The application of technologies and substances used without harming the environment with the use of wet washing and dry cleaning has been observed. From the results, a vision of best practices is proposed found in water reuse benefits associated with the management of cleaner production in terms of eco-efficiency.
\end{abstract}

Keywords: Reuse of Water. Industrial laundry. Eco-efficiency. 


\section{Introdução}

Num contexto de legislação ambiental cada vez mais estreita, a preocupação ambiental torna-se foco. A sociedade passa a cobrar de setores públicos e privados mudanças na forma gerenciamento de resíduos e a adoção de programas que resultam em desempenho ambiental adequado (SOMAVILLA, 2013). A intensa preocupação com a escassez de água leva ao aumento considerável de demanda pelo tratamento de águas residuais (GARRIDO-BARSEBA et al., 2012). Porém, nem sempre as empresas incorporam ações sustentáveis de forma espontânea. Em muitos casos os padrões de qualidade são exigidos por meio de transações comerciais (BEZERRA e MONTEIRO, 2009).

A ecoeficiência, considerada como a coerência entre eficiências econômica e ecológica visando à redução de custos empresariais e de impactos ambientais negativos (ALVES, 2010), é também uma ferramenta de apoio à tomada de decisão nas organizações (BEZERRA, 2006).

Em se tratando da questão ambiental, o relatório da Organização das Nações Unidas (ONU), apresentado na Conferência Internacional sobre a Água (1998), alertou o tema da escassez de água, que ameaça dois terços a população do planeta (BELTRAME, 2000). No processamento e nas operações de uma lavanderia industrial, é necessária a utilização de grandes quantidades de água (FREITAS, 2002; BELTRAME, 2000). Este uso excessivo, aliado a manutenção precária (válvulas com defeito, vazamentos, águas de resfriamento que fluem mesmo com a máquina parada) e equipamentos para lavagens ineficientes, são problemas que, se corrigidos, podem reduzir em $25 \%$ o consumo de água da indústria (SANIN, 1997).

O setor empresarial está consciente de que o reuso da água é uma forma não apenas de garantir crescimento sustentável para os negócios, mas é, antes disto, uma questão de sobrevivência que exige melhorias contínuas a fim de proporcionar autonomia no abastecimento de água (FIRJAN, 2006).

A reutilização da água por meio da Estação de Tratamento de Efluentes (ETE) é uma alternativa de ecoeficiência. Freitas (2002) alerta quanto à importância da escolha de tecnologias de tratamento de efluentes que respeitem restrições de processos e índices de qualidade da água.

Neste contexto, o objetivo deste artigo é analisar as práticas adotadas para o reuso de água em lavanderias industriais. A questão de pesquisa é: Quais as práticas de reuso de água adotadas por lavanderias industriais? O método de pesquisa é o estudo de caso múltiplo. Os objetivos específicos são: (i) descrever os processos de lavanderia e de tratamento de efluentes nas lavanderias industriais e; (ii) identificar a economia diária de água nestas organizações.

O artigo está estruturado da seguinte forma: na primeira seção apresentam-se o tema e os objetivos de pesquisa. Em seguida, trata-se da revisão da literatura que inclui: ecoeficiência, lavanderias industriais e suas operações, e tratamento de efluentes em lavanderias industriais. Na seção 3 apresenta-se a metodologia, e na seção 4, os resultados e discussão sobre os estudos de caso, elaborando-se ainda uma visão das melhores práticas encontradas no reuso da água, demonstrando os benefícios da gestão da produção mais limpa em termos de ecoeficiência. Por fim, na seção 5, as considerações finais e sugestões para futuras pesquisas.

\section{Revisão da Literatura}

Em lavanderias industriais, o reuso da água torna-se um fator importante para diminuir gastos e aumentar receita através da eficiência do processo. A ecoeficiência é uma maneira de garantir que medidas de gerenciamento ambiental levem a ganhos econômicos. As operações das lavanderias industriais causam impactos ambientais especialmente para os recursos hídricos, portanto, o reuso de água torna-se um imperativo.

\subsection{Ecoeficiência}

A ecoeficiência é uma filosofia de gestão empresarial que agrega o desempenho econômico e ambiental para possibilitar a produção com menor impacto sobre o meio ambiente (ALMEIDA, 2005). O conceito é definido como agregação de valor com o uso mínimo de recursos e o mínimo de poluição (HUESEMANN, 2004). 
Dyllick (2002) acrescenta ainda que é uma parte valiosa das estratégias corporativas. O conceito ganhou vasta aceitação nas últimas décadas, como uma condição necessária, embora não suficiente (WELFORD, 1997) para reduzir a degradação ambiental (WBCSD, 2000a, 2000b).

De acordo com Vellani e Riberiro (2009), para fortalecer a sustentabilidade da empresa, suas práticas ecológicas devem seguir o caminho da ecoficiência, ou seja, operações ecológicas necessitam performances em suas próprias atividades, e todos os gastos nestes aspectos precisam originar vantagens econômicas e financeiras ao negócio total.

Segundo a União das Nações Unidas para a Proteção Ambiental (UNEP, 2014), ecoeficiência é uma aplicação contínua de uma estratégia ambiental preventiva integrando processos, produtos e serviços, a fim de aumentar a eficiência total e de reduzir riscos aos seres humanos e ao meio ambiente. Também é compreendida como uma estratégia gerencial, a qual permite obter crescimento econômico, ao mesmo tempo em que são gerenciados os impactos ambientalmente negativos oriundos do processo produtivo (SOMAVILLA, 2013).

\subsection{Lavanderias Industriais}

Lavanderias industriais são sistemas complexos que, sofrem forte influência de fatores internos e externos, portanto necessitam ser avaliadas com visão sistêmica cujas variações, micro e macroambientais, podem interferir no seu planejamento e resultados (JERÔNIMO et al., 2012). O processo das lavanderias industriais inicia-se com o recebimento das roupas e termina com a expedição aos clientes das peças lavadas com características modificadas dos tecidos. Todo o processamento é sequenciado e envolve tratamentos químicos e físicos. Em seus processos, diversas atividades são contempladas, como por exemplo: enxágues iniciais e intermediários, umectação, prélavagem, lavagem, alvejamento, acidulação, amaciamento, desengomagem, secagem, centrifugação, passamento, embalagem, conserto da peça de roupa e acabamento. Em suas operações, que necessitam o recurso água, produtos químicos são utilizados, o que pode ocasionar danos ambientais (ITABOBOHY e SILVA, 2006; PICCHIAI e FARIAS, 2013).

As inovações tecnológicas investidas corroboram com a melhoria contínua dos processos de lavagem, a fim de eliminar máculas e impurezas nos tecidos, derivadas de uma série de elementos como produtos químicos, alimentos, pigmentos, poeiras atmosféricas que provocam mudanças nos processos das lavanderias, portanto devem ser revistas com certa periodicidade (PICCHIAI e FARIAS, 2013).

\subsubsection{Operações e tecnologias em lavanderias industriais}

De acordo com Cargnin (2008), é fundamental analisar o processo de lavagem e desinfecção de roupas de forma global. No estudo minucioso de cada parte integrante é possível alcançar eficiência econômica e ambiental implantando-se melhorias no processo.

Conforme a Companhia de Tecnologia de Saneamento Ambiental do Estado de São Paulo (CETESB, 2009), as entradas e saídas envolvidas nos processos de lavanderias industriais, são: insumos (água, formas de energia e produtos químicos) e externalidades (gases, particulados, vapores, efluente líquido, resíduo sólido, calor, ruído e vibração) do processo têxtil. A Figura 1 apresenta um esquema das operações e dos processos de lavanderias industriais.

De acordo Pacher et al. (2011), atualizações nos processos das lavanderias como reutilização da água, adoção de produtos biodegradáveis, remessa para reciclagem de embalagens de solventes e o tratamento adequado da água antes da evacuação para o esgoto podem atenuar o impacto sobre o meio ambiente.

A lavagem úmida apresenta riscos ao meio ambiente em uma escala menor do que a lavagem a seco, considerando que na segunda alguns produtos químicos podem prejudicar a saúde e o meio ambiente. A busca por novos produtos de lavagem menos defasados minimiza a geração de resíduos (PACHER et al., 2011). A tecnologia de produtos já permite a redução do uso de produtos químicos para produtos biológicos. A biolavagem reduz tempo, ação mecânica e temperatura, influenciando nos fatores sinergéticos. Portanto, é possível verificar que os fatores podem ser reduzidos, excluídos ou aumentados mediante a etapa do processo de lavagem (PICCHIAI e FARIAS, 2013). 
As mudanças nos processos possibilitam a redução de tempos, atividades dos equipamentos e intensidade de calor consumido, afetando os resultados em termos de sinergia. Desta forma é factível apurar reduções, exclusões ou aumento de gastos em uma lavanderia (PACHER, 2011; PICCHIAI e FARIAS, 2013).

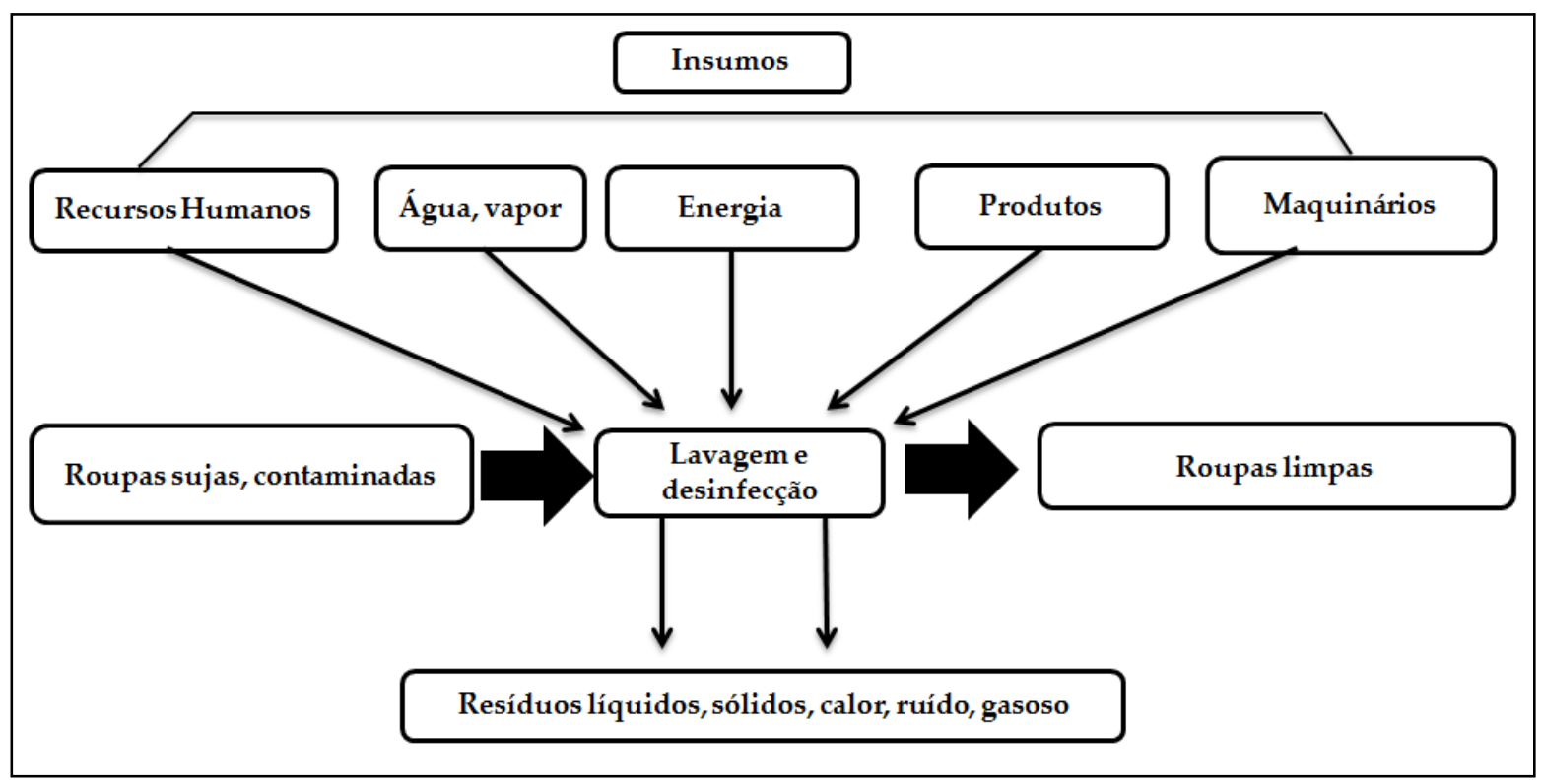

Figura 1 - Análise global do processo de lavagem e desinfecção de roupas Fonte - Baseado em Cargnin (2008) e CETESB (2009).

Para o sucesso da lavagem elementos devem ser classificados, como: características do fio, sujidades, resíduo, pigmentação, segurança sanitária e do trabalho, e podem assegurar um processo rentável. Capacitação e treinamento dos operadores para o conhecimento operacional pode evitar danos nos tecidos, acidentes e desperdícios de materiais (PICCHIAI e FARIAS, 2013).

\subsection{Reuso ou reciclagem da água}

A água é um recurso valioso que não deve ser desperdiçado. Cerca de $1 \%$ de toda a água tratada usada de forma residencial serve para beber, e o restante é empregado para lavagem em máquinas, banheiros, chuveiros, regar gramados etc. Há uma necessidade crescente de conservar água para várias finalidades (AHMAD, 2008). O reuso ou a reciclagem da água não é um conceito novo (FIRJAN, 2006).

O setor industrial é um importante usuário de água, e deve utilizá-la de forma racional e eficiente (FIRJAN, 2006). No cenário brasileiro, as externalidades ambientais do setor industrial e o rápido crescimento urbano apresentam indícios de escassez hídrica. Segundo Chen (2012), alguns países como América do Norte, Austrália, Oriente Médio, Ásia e da África, têm considerado a água reciclada como um recurso hídrico alternativo para combater problemas de escassez de água associados com o aumento da população, deterioração da qualidade da água e as mudanças climáticas.

No setor de lavanderias industriais, a água usada para a lavagem das roupas contém concentrações mais elevadas de produtos químicos, tais como: sódio, fosfato de boro, surfactantes, amônia e nitrogênio. Para tanto, o descarte desta água não tratada pode levar a danos ambientais nem representar ameaça à saúde. O conceito de três Rs, ou seja, Reduzir, Reutilizar e Reciclar é uma parte da produção mais limpa que se concentra na prevenção da poluição na fonte (AHMAD, 2008).

Segundo Hoinkins (2008), as lavanderias industriais emitem altas quantidades de águas residuais e podem ser consideradas indústrias que utilizam de forma intensa a água reutilizada. É essencial estabelecer planos de gerenciamento que contém todas as etapas de manejo (acondicionamento, transporte e destinação final), políticas de treinamento, segurança, minimização de resíduos, combate 
ao desperdício, incentivo a reciclagem, busca de parcerias para a comercialização dos resíduos entre outras (SANCHEZ, 2003).

Os principais benefícios ambientais e sociais resultantes da reciclagem de água são: i) redução do lançamento de efluentes industriais em cursos d'água, possibilitando melhorar a qualidade; ii) redução da captação de águas superficiais e subterrâneas, possibilitando uma situação ecológica mais equilibrada; iii) aumento da disponibilidade de água para usos mais exigentes, como abastecimento público, hospitalar, etc; iv) conformidade ambiental em relação a padrões e normas ambientais estabelecidos, possibilitando melhor inserção dos produtos brasileiros nos mercados internacionais; v) mudanças nos padrões de produção e consumo; vi) redução dos custos de produção; vii) aumento da competitividade do setor; e viii) habilitação para receber incentivos e coeficientes redutores dos fatores da cobrança pelo uso da água.

De acordo com Hernández-Sancho; Sala-Garrido (2009) é do conhecimento comum que o reuso de água é benéfico, não só porque permite recursos hídricos para ser recuperado, mas também porque reduz os impactos ambientais.

\subsubsection{Aspectos legais da gestão de recursos hídricos e padrões de emissões de efluentes}

A vigência de normas e leis relacionadas à utilização dos recursos hídricos tem como objetivo assegurar uma relação harmônica entre as atividades humanas e o meio ambiente, a fim de permitir um equilíbrio adequado entre os segmentos da sociedade ou setores econômico. O uso de alternativas tecnológicas para reciclagem ou reuso de água poderá reduzir custos de produção e fomentar a recuperação, preservação e conservação de recursos hídricos e dos ecossistemas urbanos (FIRJAN, 2006).

No Brasil, a Lei nº 9.433/97 criou o Sistema Nacional de Gerenciamento de Recursos Hídricos que tem como objetivos: i) coordenar a gestão integrada das águas; ii) arbitrar administrativamente os conflitos relacionados com os recursos hídricos; iii) implementar a Política Nacional de Recursos Hídricos; iv) planejar, regular e controlar o uso, a preservação e a recuperação dos recursos hídricos; e v) promover a cobrança pelo uso de recursos hídricos. O órgão que fiscaliza a gestão dos recursos hídricos no país é a Secretaria Executiva do Conselho Nacional de Recursos Hídricos. Indústrias que fraudarem as medições dos volumes de água utilizados ou declararem valores diferentes dos medido serão penalizadas (BRASIL, 1997). Esta lei não se refere ao reuso da água, mas apenas ao uso racional desse recurso e, portanto uma lacuna quanto à obrigatoriedade das empresas em reaproveitarem águas residuais.

As Resoluções do Conselho Nacional do Meio Ambiente (CONAMA) 357/2005 e 430/2011 definem efluentes e as condições e padrões para seu lançamento em corpos d'água. Assim, efluentes são despejos líquidos provenientes de diversas atividades ou processos (BRASIL, 2005; 2011). Alguns parâmetros relevantes para emissões de efluentes são: $\mathrm{pH}$ entre 5 e 9; temperatura inferior a $40^{\circ} \mathrm{C}$; materiais sedimentáveis até $1 \mathrm{ml} / \mathrm{l}$ em teste de uma hora; regime de lançamento com vazão máxima de até 1,5 vez a vazão média do período de atividade diária do agente poluidor.

Vale ressaltar que no cenário Brasileiro, não há uma lei federal referente ao reuso de água, conforme afirma a CETESB-SP (2015), o governo federal está buscando uma forma de regulamentar a utilização da água de reuso. A normatização já está sendo debatida nos estados de São Paulo e do Rio de Janeiro.

\subsection{Tratamento de Efluentes em lavanderias industriais}

Segundo Vellani e Ribeiro (2009), programas direcionados ao tratamento dos efluentes são exemplos de ações ecológicas e as quais podem ser executadas para transformar resíduos em insumo ou em produto, anular a consequência tóxica dos mesmos, ou diminuir o lançamento de resíduos no meio ambiente. Portanto é necessário considerar simultaneamente questões técnicas, econômicas, sociais e ambientais (GARRIDO-BARSEBA et al., 2012).

Neste contexto, eficiência está relacionada ao uso mínimo de recursos (entradas) e de se alcançar uma determinada produção (saída), de acordo com a tecnologia existente. Portanto, um projeto de estação de tratamento de efluentes é um exercício complexo no qual se deve considerar uma gama de 
questões paraconseguir uma desejada qualidade do efluente (HERNÁDEZ-SANCHO e SALAGARRIDO, 2009; GARRIDO-BARSEBA et al., 2012).

O tratamento de efluentes implica basicamente na aplicação de técnicas para atingir eficiência de remoção de poluentes e reduzir custos operacionais com confiabilidade técnica (GARRIDO-BARSEBA et al., 2012). De acordo com Hernández-Sancho; Sala-Garrido (2009), a eficiência de reuso industrial depende de como os custos de manutenção e da gestão dos resíduos são acompanhados e tratados.

Os processos de tratamento mais comuns são os primários, que permitem a remoção de sólidos em suspensão, incluindo sedimentação e floculação, e os secundários, que envolvem processos biológicos e oxidação de matéria orgânica. A escolha de qual processo utilizar dependerá das características do efluente, da qualidade desejada, da área e tecnologia adequada (BELTRAME, 2000). Segundo Younes et al. (2012), utilizar somente o tratamento primário é eficaz mas é caro e cria um problema de escoamento com a formatação de uma lama concentrada. Existe também o tratamento biológico, que trata da remoção dos chamados micropoluentes, "presentes em baixas concentrações na fase aquosa, na faixa de microgramas por litro" (SANT'ANNA JR., 2013), que utiliza microorganismos como fungos e bactérias para a decomposição de materiais orgânicos, bem como tecnologias avançadas de nanofiltros para a remoção de agentes microbianos.

\section{Metodologia e Resultados}

Esta pesquisa apresenta uma abordagem predominantemente qualitativa e aplicada (GIL, 2010), direcionando-se à investigação da ecoeficiência no reuso de água em lavanderias industriais. Trata-se de um estudo descritivo (MEDEIROS, 2011; BARROS e LEHFELD, 2000). Para a sua realização, foi utilizado o estudo de casos múltiplos.

Nesta abordagem busca-se obter informações sobre a perspectiva dos indivíduos, bem como, interpretar o ambiente em que o problema acontece, sendo o ambiente natural dos indivíduos o objeto de pesquisa, no qual se fazem observações e coletam-se evidências (MIGUEL, 2012; OLIVEIRA, 2012).

O estudo de caso é abordagem empírica empregada para a investigação de fenômenos atuais, através da análise de um ou mais objetos em um contexto real possibilitando mais conhecimento sobre o fenômeno (GIL, 2010; OLIVEIRA, 2010; MIGUEL, 2012).

A coleta de dados aconteceu durante o período agosto a novembro de 2014. O estudo de caso iniciou com a pesquisa de campo através de visitas pontuais à lavanderias industriais, após conhecer a estrutura física e os processos das lavanderias, foram elaboradas as questões para entrevista. As empresas objetos deste estudo foram duas organizações pertencentes ao setor de lavanderias industriais atuantes no Rio Grande do Sul, denominadas de Empresa A e Empresa B. A Tabela 1 apresenta o resumo do protocolo de pesquisa.

Tabela 1 - Resumo do protocolo de pesquisa

\begin{tabular}{cl}
\hline Tema & Desenvolvimento \\
\hline Lavanderias Industriais & Descrição do setor \\
Ecoeficiência & Fazer mais usando menos - economia no consumo de água e energia \\
Água & Reuso da água e aspectos legais \\
Tratamento de Efluentes & Descrição de tratamento de efluentes \\
Vantagens e Melhores & $\begin{array}{l}\text { Identificação das vantagens e melhores práticas no reuso da água nas } \\
\text { Práticas }\end{array}$ \\
\hline
\end{tabular}

Fonte: Elaboração própria

A Figura 2 evidencia a estruturação da pesquisa pelos autores, apresentando as etapas do estudo e seus respectivos conteúdos. 


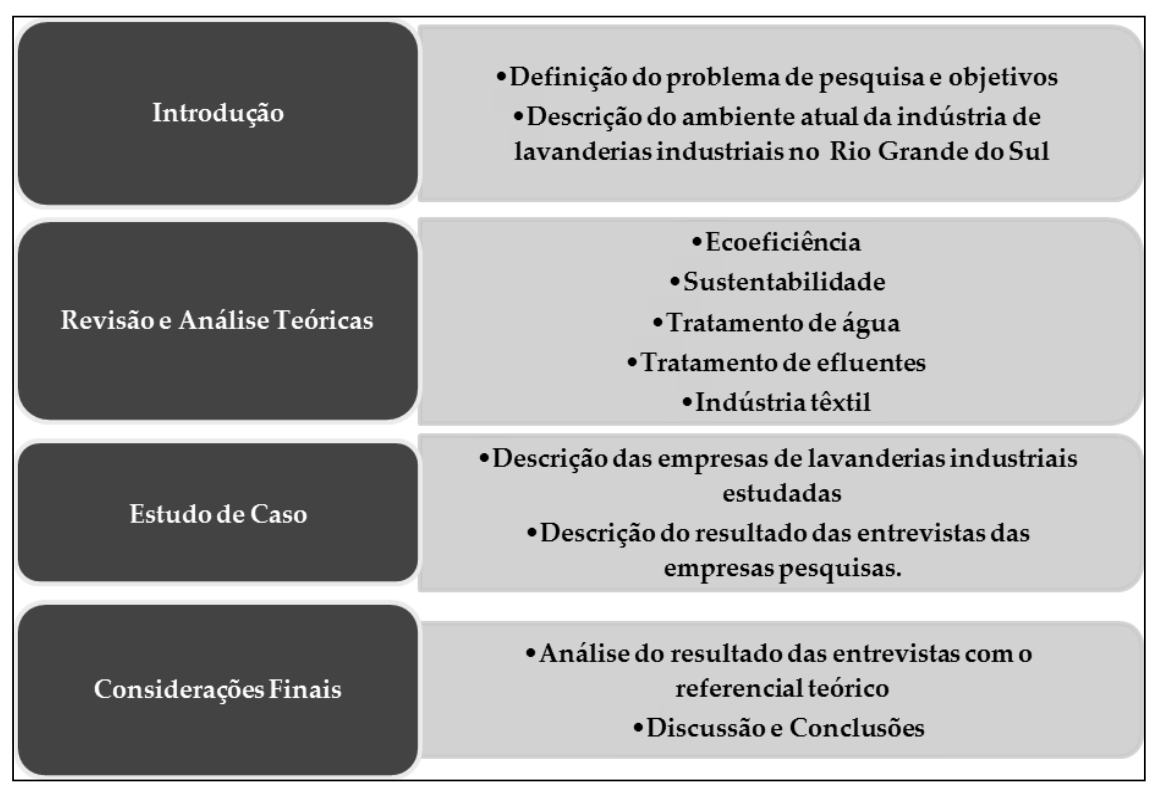

Figura 2 - Estruturação da pesquisa

Fonte: Elaboração própria

Após a definição dos temas chaves, entrevistas não estruturadas foram realizadas "in loco" com gerentes e diretores, propondo-se perguntas abertas. Em um segundo contato, entretanto, foi utilizado um guia com os constructos, com o objetivo de seguir os tópicos importantes e refinar a coleta de dados.

\subsection{Empresa A}

É uma empresa do ramo de higienização têxtil (lavanderia) localizada no interior do Rio Grande do Sul, que começou sua trajetória em 1999. Em 2014 foi fundada uma Associação de Seis Hospitais para adquirir uma planta industrial inativa que inclui área, maquinário e demais instalações. A associação é composta pelas seguintes organizações: Grupo Hospitalar Conceição (GHC), Hospital São Lucas da PUC, Complexo Hospitalar Mãe de Deus, Hospital Ernesto Dornelles, Hospital de Clínicas de Porto Alegre e Hospital Divina Providência. No cenário brasileiro, é a primeira experiência em gestão compartilhada em áreas hospitalares não concorrenciais e, com isso, permite a troca de experiências e o aperfeiçoamento da gestão. Atualmente, a associação conta com 320 colaboradores atuando na higienização dos enxovais hospitalares, o que incluem lençóis, toalhas, uniformes e outros.

A planta industrial fica numa área de 11 hectares. Apresenta capacidade instalada para lavar 30 toneladas/dia de têxteis, atualmente higieniza de 20 a 25 toneladas/dia e utiliza 450 metros cúbicos de água por dia. A associação cumpre as normas de licenciamento ambiental. Conta com sistemas para tratamento de efluentes e açudes naturais que garantem a continuidade dos trabalhos em qualquer situação, atendendo a todas as normas da Agência Nacional de Vigilância Sanitária (ANVISA).

Quanto à logística, a frota é composta por veículos que possuem licença de operação emitida pela (Fundação Estadual de Proteção Ambiental do Rio Grande do Sul (FEPAM)) para transporte de resíduos - Classe I. O ciclo para processar e encaminhar para o hospital é no máximo 24h.

\subsection{Processo da Lavanderia Industrial Hospitalar}

O processo de lavagem é $100 \%$ lavagem úmida, utilizando água e produtos convencionais. Nas áreas da empresa atuam operadores de máquinas lavadoras, secadoras, calandras, dobradeira automática, passadoria com prensas e ferro a vapor, coordenadores de área, um supervisor de produção, e um gerente. A área física da lavanderia cumpre as normas técnicas e legais do Ministério da Saúde (BRASIL, 1996) [Portaria nº 1.884/GM de 11.11.1994], possuindo barreira física entre área contaminada e área limpa. Possui também a liberação da ANVISA, conforme RDC 306 (ANVISA, 
2004), e da FEPAM, para seu funcionamento, possuindo uma Estação de Tratamento de Efluentes. A Figura 3 apresenta o processo da lavanderia industrial.

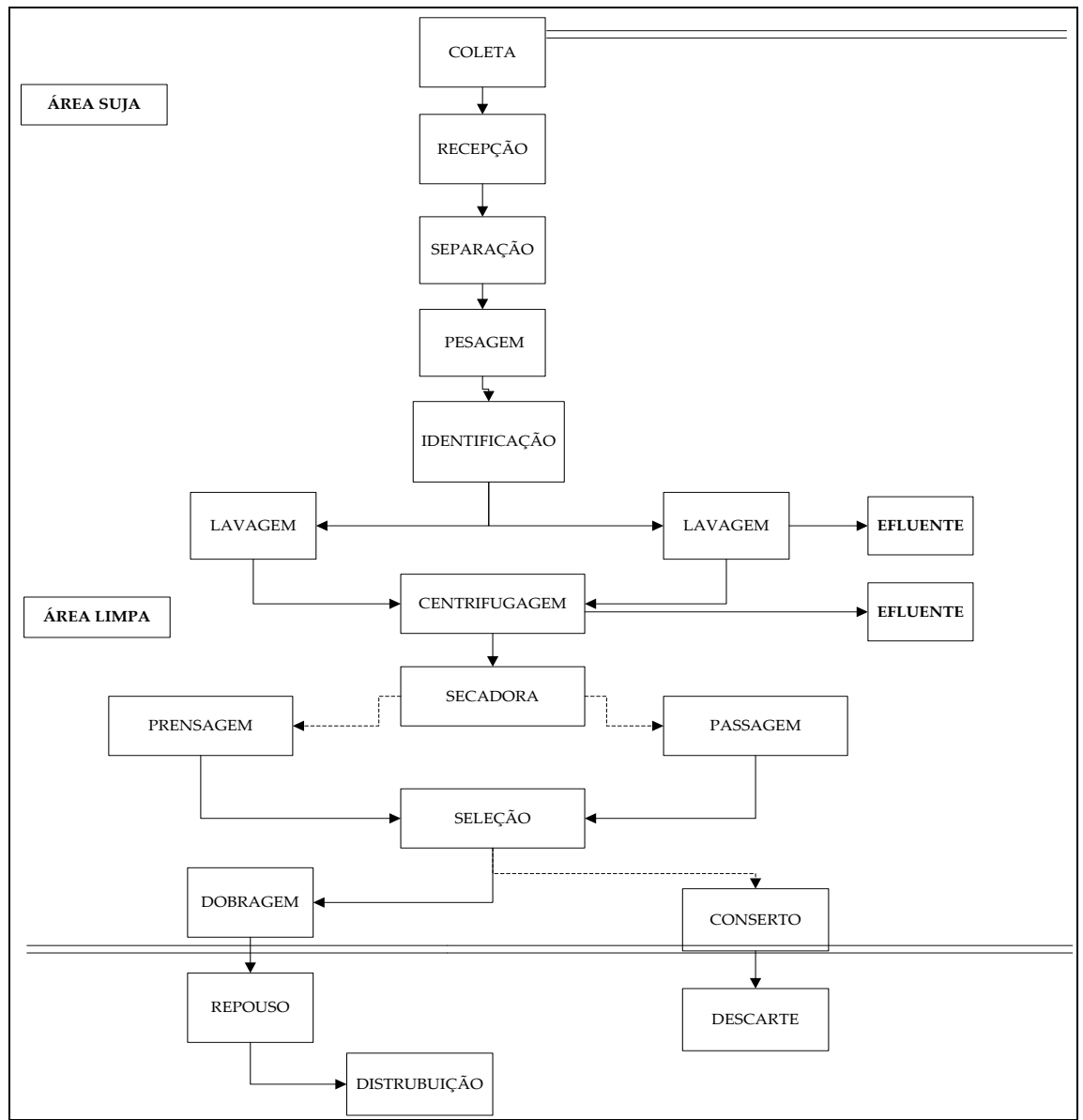

Figura 3 - Fluxograma do processo de lavagem industrial de roupas hospitalares da empresa A

Fonte: Elaboração própria

A área suja é composta pelos processos de: coleta do material, recebimento do material, separação, pesagem e identificação pelo saco impermeável de cada hospital com sua coloração. Quanto ao recebimento, o funcionário do setor separa os cobertores das roupas: lençol, uniforme e toalha. As roupas são classificadas quanto à sujidade e cada sujidade tem processo específico para remoção, sendo:

- Sujidade pesada: as roupas com resíduos de sangue, fezes e urina;

- Sujidade leve: as roupas que não têm esse tipo de resíduos.

Segundo o Ministério da Saúde (1986), o processo de lavagem de roupa com sujidade leve e pesada devem seguir os seguintes procedimentos:

○ Roupa com sujidade leve: lavagem, alvejamento/desinfecção, $1^{\underline{0}}$ enxágue, $2^{\mathrm{o}}$ enxágue, acidulação, amaciamento/desinfecção;

○ Roupa com sujidade pesada: umectação, $1^{\underline{0}}$ enxágue, $2^{\underline{0}}$ enxágue, pré-lavagem, enxágue, alvejamento/desinfecção, lavagem, $1^{\circ}$ enxágue, $2^{\underline{0}}$ enxágue, acidulação amaciamento/desinfecção.

Para caracterizar o produto, cada hospital possui sacos impermeáveis de cores diferentes. Neste setor há dois funcionários exclusivos para trabalhar no processo de - recebimento e lavagem - e um exclusivo para retirar as manchas. Nesta etapa $60 \%$ do material apresenta sujidade pesada o que decorre usualmente do tempo de espera para que o material chegue até a lavanderia. O sangue apresenta $35 \%$ sujidade leve e $15 \%$ do material sujo superpesado. A Tabela 2 apresenta o volume de higienização da lavanderia estudada. 
Souza et al.: Análise das práticas de reuso de água residual...

Tabela 2 - Volume de higienização

\begin{tabular}{lc}
\hline \multicolumn{1}{c}{ Grupo } & Volume efetivo (kg/dia) \\
\hline Hospitalar Conceição (GHC) & 10.000 \\
Hospital São Lucas da PUC & 6.000 \\
Complexo Hospitalar Mãe de Deus & 3.000 \\
Hospital Ernesto Dornelles & 1.000 \\
Hospital de Clínicas & ----- \\
Hospital Divina Providência & 2.000 \\
Total & $\mathbf{2 2 . 0 0 0}$ \\
\hline
\end{tabular}

Fonte: Elaboração própria

Com característica distinta da lavanderia convencional, a lavanderia industrial apresenta dois setores de trabalho: área suja e área limpa. A distinção destes setores faz necessário para que a roupa já higienizada não entre em contato com as sujas evitando contaminação (NASCIMENTO, 2011).

Quanto à área limpa é composta pelos processos de: lavagem, centofugação, secagem, prensagem, passagem, seleção, dobragem, repouso e distribuição. No método de higienização para desinfecção e na oxidação de manchas, utiliza-se o processo de termo desinfecção a 80 graus Celsius com peróxido de Hidrogênio, também favorece o aumento do tempo de vida útil do enxoval e garante uma perfeita higienização têxtil. O reaproveitamento da água tratada é de $80 \%$.

\subsubsection{Processos na Estação de Tratamento de Efluentes (ETE)}

No processo da Estação de Tratamento de Efluentes, o efluente bruto é acumulado de todos os processos de lavagem gerado pelas máquinas. O primeiro estágio do efluente é o peneiramento de sólidos grosseiros visando retirar materiais de granulometria facilmente visível, por exemplo, compressas e pedaços de roupas. Após, ainda o efluente vai para o segundo tipo de peneiramento de micropartículas visando retirar fuligens da roupa e fios de algodão.

Em seguida é realizada a homogeneização de modo que o efluente bruto vá para ETE com uma característica física uniforme. O efluente é transferido para a ETE com pH em torno de 6 e, após o primeiro tanque, o pH corrigido para 8,5. No segundo tanque de floculação é adicionado policloreto de alumínio (PAC) que tem como objetivo formar flocos com a matéria orgânica do efluente. Nesse tanque é adicionado polímero para acelerar a sedimenttação.

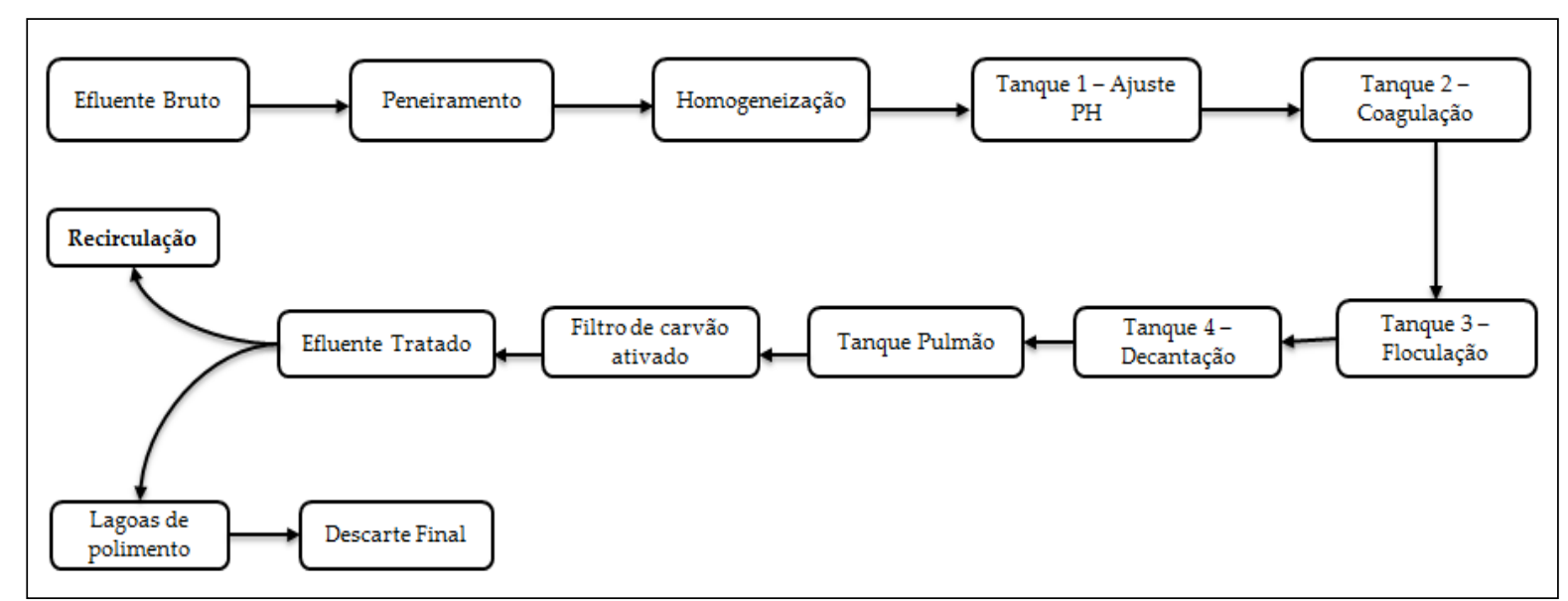

Figura 4 - Fluxograma da Estação do Tratamento de Efluentes da empresa A

Fonte: Elaboração própria

No tanque seguinte o efluente passa por três decantadores ao mesmo tempo através da gravidade. Na etapa seguinte, vai para tanque pulmão. Depois do tanque pulmão, o efluente por lâmpadas de 
ozônio onde se realiza a oxidação das bactérias e depois retorna para o tanque pulmão, assim sucessivamente, realizando um ciclo. Posteriormente, por bombeamento, é submetido a dois filtros de carvão ativado e areia para remoção das micropartículas que ainda permanecerem no efluente.

Ao final do processo, o efluente está tratado para retornar ao processo de lavagem industrial. Seu armazenamento é feito em um tanque com capacidade máxima de $600 \mathrm{~m}^{2}$ de água, e é adicionado hipoclorito de sódio (desinfetante) para que não haja proliferação de bactérias. O efluente para descarte em lagoas de polimento não apresenta resíduo de hipoclorito. A Figura 4 ilustra o processo da ETE da empresa A

\subsection{Empresa B}

A empresa atua prestação de serviços em lavanderia industrial, atuando na locação de uniformes, toalhas, industriais, toalhas contínuas e tapetes além de higienização de Equipamento de Proteção Individual (EPI's), embalagens industriais e equipamentos para aeronaves, entre outros serviços. Possui matriz na Região Metropolitana de Porto Alegre/RS e dispõe de filiais nos estados da Bahia, Paraná e Pernambuco. Está estabelecida em uma área de $14.000 \mathrm{~m}^{2}$ e com área construída de $10.000 \mathrm{~m}^{2}$. Apresenta capacidade instalada para lavar 50 toneladas/dia de têxteis e atualmente higieniza 44 a 46 ton./dia, utilizando 400 metros cúbicos de água/dia. Possui licenciamento ambiental com área para sistemas para tratamento de efluentes advinda do aquífero Guarani, e que garante a permanente utilização e reutilização, atendendo a todas as normas da ANVISA.

A empresa é certificada pelas normas ISO 9001 e ISO 14001, atualmente conta com uma mão-deobra de 700 colaboradores. Possui uma carteira de 12.000 clientes, cerca de 2.000 .000 unidades de peças mensalmente são processadas.

A lavanderia industrial possui vinte anos de atuação no mercado, e é uma empresa privada de médio porte. Reusar efluentes é a atividade que a empresa considera a chave para intensificar os processos na lavanderia e reduzir o consumo de água do aquífero onde é captada. $\mathrm{O}$ reaproveitamento da água tratada é de $40 \%$.

A empresa investe $20 \%$ da receita anual em novos equipamentos e novas tecnologias, possui uma atenção especial ao treinamento do pessoal, uma média anual de 40 horas de capacitação.

Quanto à cadeia de suprimentos a lavanderia desenvolve os fornecedores solicitando amostra para análise de produtos, exige certificados ISO 9001 e ISO 14001 e avaliações periódicas. Nos serviços ambientais a empresa exige dos prestadores de serviços licenças de operação e de transporte pelos órgãos ambientais vigentes no Estado.

A empresa conta anualmente com um Plano de Manutenção Preventiva controlado através de gerenciamento de software para máquinas e equipamentos. Para reduzir o consumo de energia elétrica, a lavanderia teve suas máquinas equipadas com inversores de frequência, que visam reduzir o pico de energia elétrica. Para gerar vapor a empresa tem caldeira com alimentação a lenha advinda de área de reflorestamento.

\subsubsection{Processo de Lavagem}

O processo de lavagem divide-se em: $20 \%$ dos casos, lavagem a seco, à base de produtos químicos, como percloroetileno, e $80 \%$ lavagem úmida, utilizando água e produtos convencionais. A Agência Nacional Vigilância Sanitária (ANVISA) estabeleceu, pela RDC 161 de 23/06/2004, regras para a utilização do percloroetileno para proteger o meio ambiente e a saúde da população e dos trabalhadores.

A empresa investiu nas mais modernas máquinas ecológicas disponíveis no mercado, compostas de injeção automática de percloroetileno para que não haja excessos e o produto químico aplicado nas lavagens úmidas é totalmente reciclado. Com foco na padronização dos processos, eliminação de desperdício todas as máquinas de lavar são dotadas de dosadores automáticos de produtos químicos.

A empresa conta com operadores nas máquinas lavadoras, secadoras, calandras, dobradeiras automáticas e na passadoria, possui dois coordenadores de área, um supervisor de produção, e um gerente. Desde 2002 possui uma estrutura de tratamento de efluentes líquidos para prover tratamento diário de $400 \mathrm{~m}^{3}$ dos efluentes resultantes dos processos da lavanderia industrial, para que depois do 
tratamento sejam utilizados no reuso interno. A lavanderia possui certificado para tratamento de efluentes industriais e segue condições e padrões de lançamento de efluentes conforme resolução $\mathrm{n}^{\mathbf{0}}$ 430/11 (CONAMA, 2011), da FEPAM, bem como, outros alvarás e licenças necessários para a sua atuação no mercado. A Tabela 3 apresenta as unidades de estudo, assim como - o volume efetivo. Salienta-se que no estudo de caso apenas a Unidade Matriz foi estudada.

Tabela 3 - Volume de higienização por unidades (Matriz e filiais) da empresa B

\begin{tabular}{cc}
\hline Unidade & Volume efetivo (kg/dia) \\
\hline Unidade Matriz & 15.000 \\
Unidade Filial 1 & 11.000 \\
Unidade Filial 2 & 11.000 \\
Unidade Filial 3 & 7.000 \\
Total & $\mathbf{4 4 . 0 0 0}$ \\
\hline
\end{tabular}

Fonte: Elaboração própria

Nos processos padronizados da empresa, podem-se destacar dois pontos importantes em unidades de ação: na área contaminada e na área limpa. Quanto à separação para lavagem as roupas são classificadas quanto ao padrão de lavagem a seco ou lavagem úmida, quanto à sujidade - cada sujidade tem processos específicos para higienização. A separação do material é definida pelo seguinte critério para o procedimento de higienização é definido pelo resultado do efluente:

- Toalhas contínuas e toalhas de banho - São materiais sem óleo e o recebimento na planta é de 20 $\%$

- Toalhas industriais e EPIs à base de água e o recebimento na planta é de $80 \%$. A Figura 5 apresenta o processo da lavanderia industrial da empresa B.

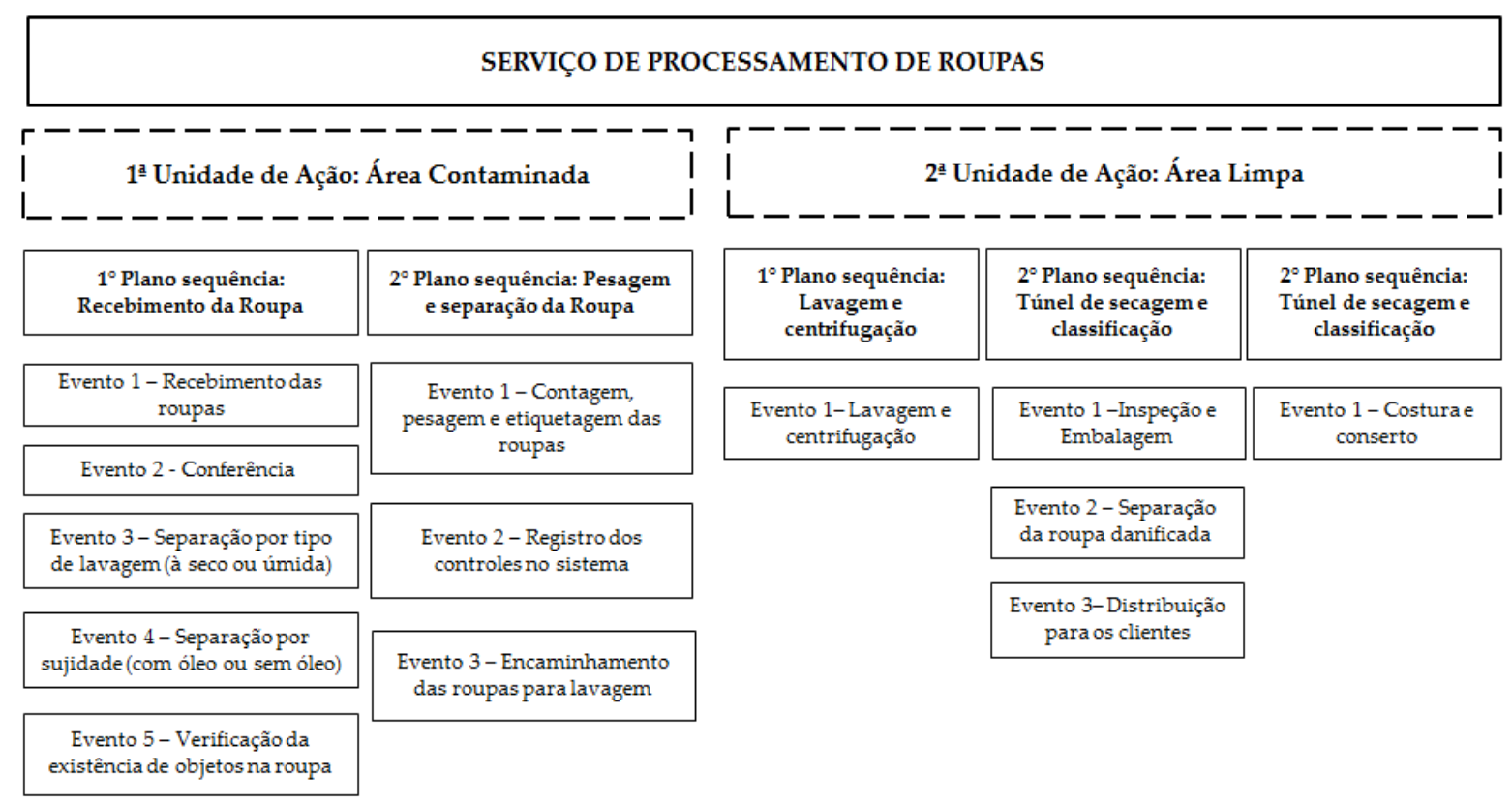

Figura 5 - Árvore plano-sequência do processo de lavagem industrial de roupas da empresa B Fonte: Elaboração própria 


\subsubsection{Processos na Estação de Tratamento de Efluentes (ETE)}

A empresa utiliza o tratamento de efluentes primário e secundário. No primário, o tratamento físico-químico é constituído das seguintes etapas:

1. Preliminar - Fase com onde é separado o óleo previamente.

2. Equalização - Visa à homogeneização e equalização de todas as cargas diárias dos efluentes gerados pela adição de produtos químicos.

3. Floculação/Coagulação - Serve para desestabilizar pequenas partículas e decantá-las.

4. Decantação primária - Na etapa da decantação, as particuladas sólidas formadas na floculação são eliminadas por ação da gravidade.

5. Filtração - Desidratação e prensagem dos flocos decantados, ou seja, passagem da água por um leito de material granular, através do qual ocorre a separação das partículas presentes na água. É utilizado um filtro-prensa.

Nesse estágio, a matéria poluente que permanece na água encontra-se em dimensões reduzidas, normalmente formadas por coloides, o que a impede de ser removida apenas por processos físicoquímicos. A partir de então ocorre o tratamento secundário, constituído das seguintes etapas:

1. Oxidação- Consiste em misturar os efluentes sanitários e o clarificado do pré-tratado.

2. Aeração/Arejamento - Este processo consiste em colocar a água em contato estreito com a fase gasosa, fornecendo oxigênio para os organismos vivos do tratamento e desta forma promover a redução das cargas químicas do efluente através da formação de flocos de materiais biodegradados.

3. Desnitrificação - Nesta fase os contaminantes nitrogênio e fósforo são removidos do efluente.

4. Decantação secundária - Nesta fase ocorre é onde se dá a remoção da matéria em suspensão, através da separação sólido-líquido. O lodo formado regressa para a primeira etapa de oxidação e o efluente tratado é conduzido para o rio dentro dos padrões de atendimento exigidos pelas entidades ambientais.

5. Reuso parcial do efluente

A Figura 6 ilustra o processo de Tratamento de Efluentes na empresa B:

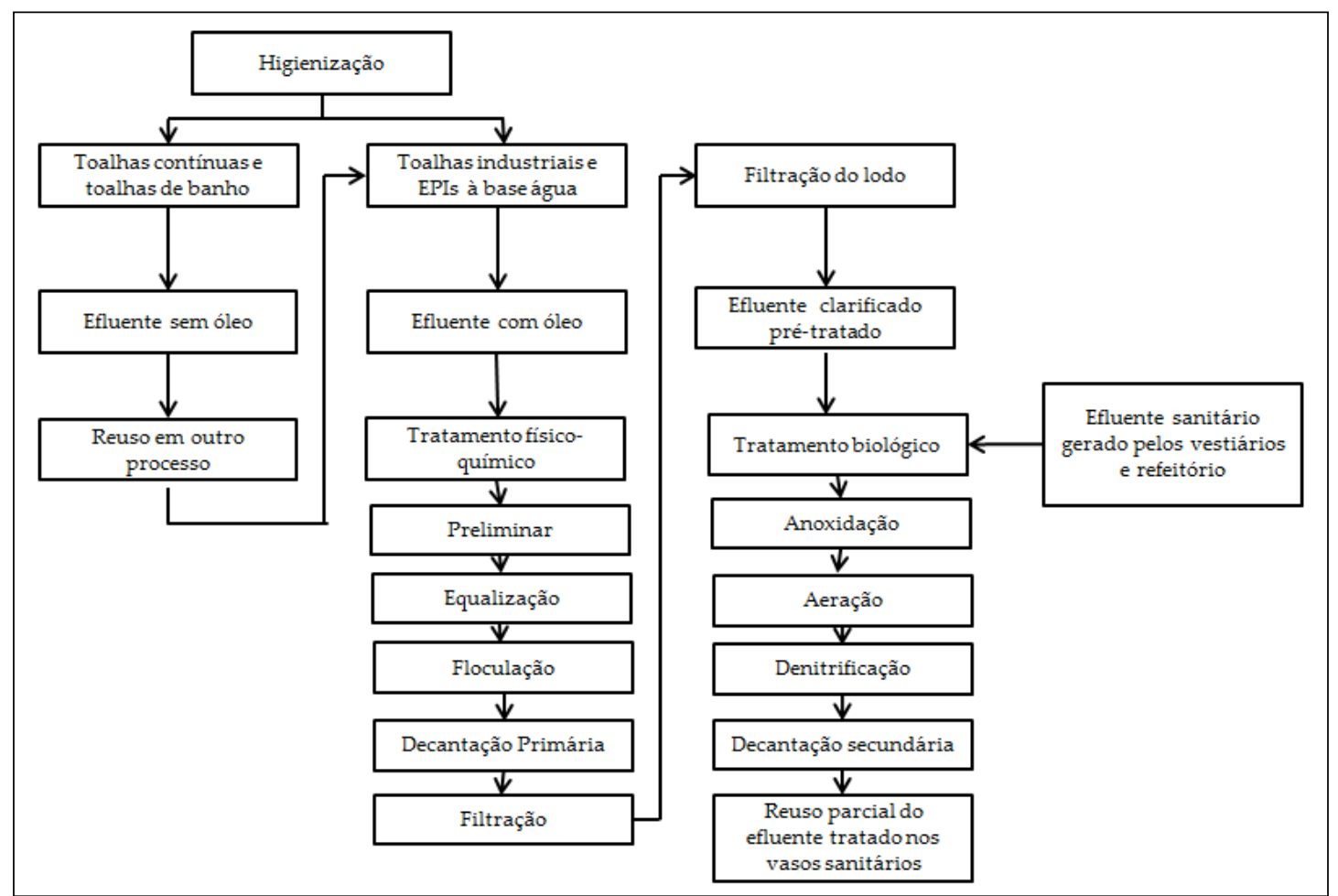

Figura 6 - Fluxograma da Estação do Tratamento de Efluentes da empresa B

Fonte: Elaboração própria 


\section{Discussão dos Resultados}

\subsection{Comparação de desempenho do tratamento de efluentes das empresas A e B}

A partir dos levantamentos realizados, é possível comparar o desempenho das empresas A e B. A empresa A como apresenta uma economia de água de $R \$ 1.278,00 /$ dia já a empresa $B$, apresentam como efeito uma economia de $\mathrm{R} \$ 641,60 /$ dia com redução de custos associados ao uso de produtos químicos, energia, geração de lodo e entre outros. As tecnologias na ETE com o uso de filtros de carvão ativado permitem maior economia e eficiência do processo. A temperatura da água na saída de ETE da empresa A é $18^{\circ} \mathrm{C}$ e pH de 8,5 e na empresa $\mathrm{B}$ é de $20^{\circ} \mathrm{C}$ e pH de 7,5 . O pH e a temperatura da água são variáveis importantes utilizadas no controle das estações de tratamento de efluentes.

A empresa A em sua totalidade utiliza a lavagem úmida, acarretando ao meio ambiente uma escala menor de degradação, conforme ilustra (PACHER et al., 2011). Já a empresa B utiliza nas lavagens úmidas produtos químicos totalmente biodegradáveis, e nas lavagens a seco o solvente utilizado pode ser reutilizado, consistindo atualmente na forma de higienização mais ecologicamente correta, já que permite a utilização de muitas vezes. Com o produto químico percloroetileno a empresa B utiliza máquinas com injeção eletrônica de quantidade de produto para que não ocorram excessos. A Tabela 4 apresenta os resultados obtidos com as práticas utilizadas pelas empresas:

Tabela 4 - Resultados obtidos com reuso da água nas empresas A e B

\begin{tabular}{c|c|c}
\hline & \multicolumn{2}{c}{ REUSO DA ÁGUA } \\
\hline EMPRESA A & EMPRESA B \\
\hline $\begin{array}{c}\text { Economilização da água/dia } \\
\text { água/dia }\end{array}$ & $450 \mathrm{~m} 3$ & $400 \mathrm{~m} 3$ \\
\hline Economia dia (R\$) & $80 \%$ & $40 \%$ \\
\hline $\begin{array}{c}\text { Tecnologias utilizadas } \\
\text { Temperatura saída da }\end{array}$ & $\begin{array}{c}\text { Filtro de carvão ativado } \\
\text { e areia }\end{array}$ & $\begin{array}{c}\text { Filtro de carvão ativado e areia } \\
\text { Máquina a seco ecológica } \\
\text { Sistema de dosadores automáticos } \\
\text { Software Gerenciamento de manutenção } \\
\text { Utilização de produtos biodegradáveis nas } \\
\text { lavagens úmidas. }\end{array}$ \\
\hline PH de saída & $1.278,00$ & ${ }^{\circ} \mathrm{C}$ \\
\hline Tipo de lavagem & 8,5 & ${ }^{\circ} \mathrm{C}$ \\
\hline
\end{tabular}

Fonte: Elaboração própria

A empresa A utiliza $450 \mathrm{~m}^{3}$ e reusa $80 \%$ deste total, segundo o Departamento Municipal de Água e Esgoto de Porto Alegre (DMAE, 2014), órgão que fornece água tratada à empresa $\mathrm{A}$, a tarifa do valor do metro cúbico para a faixa de consumo entre 401 a $500 \mathrm{~m}^{3}$ é de $\mathrm{R} \$ 3,55$. Para tanto, multiplicando o valor do metro cúbico ( $R \$ 3,55)$ por $80 \%$ da quantidade de água a empresa economiza $R \$ 1.278,00 /$ dia. Em contrapartida, segundo a Companhia Riograndense de Saneamento (CORSAN, 2014), responsável pelo fornecimento de água à empresa $B$ o valor do metro cúbico para a categoria industrial até $1000 \mathrm{~m}^{3}$ é de $R \$ 4,01$, ou seja, reutilizando $40 \%$ do total de água e multiplicando pelo valor do metro cúbico a empresa B economiza $\mathrm{R} \$ 641,60$. 


\section{Conclusões}

O presente artigo teve como objetivo analisar as práticas quanto ao reúso da água em lavanderias. Para tanto, descreveram-se os processos de lavanderia e de tratamento de efluentes e identificou-se a economia diária em cada uma das empresas estudadas. Avalia-se que as empresas possuem visões adequadas, em seus negócios, com relação aos recursos disponíveis e utilizados. Percebe-se a importância dos investimentos feitos em benefício da sustentabilidade. Destaca-se a impossibilidade de comparação de todos os requisitos e características de processos das duas empresas, em virtude, das atividades serem diferentes, uma hospitalar e a outra com processo industrial.

As empresas estudadas seguem a Resolução Conama no 430/11 que dispõe sobre as condições e padrões de lançamento de efluentes. Na empresa A não se realiza o processo de lavagem à seco, já na empresa B esses processos compõem $20 \%$ dos casos. Este processo pode apresentar riscos devido a utilização pelas organizações de produtos químicos os quais podem ser prejudiciais tanto social quanto ambientalmente. Contudo, observou-se na empresa B que o insumo utilizado na lavagem a seco é totalmente reciclado, comprovando-se a utilização de práticas ambientalmente favoráveis no processo de higienização.

A lavanderia A reaproveita $80 \%$ da água em seus processos com o tratamento de efluentes, enquanto que a lavanderia B apenas $40 \%$, isto porque na ETE da lavanderia B encontram-se muito mais produtos químicos e óleo, advindos dos processos de lavagem de têxteis de inúmeros clientes de diferentes ramos de atuação, enfrentando desta forma a dificuldade de otimização no tratamento para maior aproveitamento no reuso da água em seus processos.

Faz-se importante estar sempre atento às inovações tecnológicas dos insumos utilizados nos processos de lavagem: desenvolver junto a fornecedores novos produtos menos impactantes ao meio ambiente; estar alerta aos lançamentos de novos equipamentos no mercado; dominar legislação ambiental e sanitária; fomentar qualidade de vida nos colaboradores e em cada processo no ambiente Fabril. Para isso, investimentos necessitam ser administrados para treinamento e aquisição de novos equipamentos e novas tecnologias. Estas ações podem ser aplicáveis em outras lavanderias industriais para que possam objetivar otimização dos processos no reuso da água, economia financeira e redução dos impactos ambientais.

Para trabalhos futuros, sugere-se analisar o processo de lavagem identificando-se as melhores práticas utilizadas em lavanderias com processos e escalas semelhantes.

\section{Referências}

ACEVEDO, C. R.; NOHARA, J. J. Como fazer monografias: TCC, dissertações e teses. 4 ed. São Paulo: Atlas, 2013.

ALMEIDA, F. O Bom negócio da sustentabilidade. 3 ed. Rio de Janeiro: Nova Fronteira, 2005.

ALVES, J. Ecoeficiência como fator de competitividade em micro e pequenas empresas: um estudo de caso no setor de serviços automotivos, em Recife/PE [dissertação]. Recife: Universidade Federal de Pernambuco; 2010. 120 p.

ANDRADE, M.M. Introdução à metodologia do trabalho científico: elaboração de trabalhos na graduação. 10 ed. São Paulo: Atlas, 2010.

ANVISA - Agência Nacional de Vigilância Sanitária.. Resolução da Diretoria Colegiada - RDC № 306, DE 7 DE DEZEMBRO DE 2004. Disponível em: http://portal.anvisa.gov.br/wps/wcm/connect/10d6dd00474597439fb6df3fbc4c6735/RDC+N\%C2\%B A+306,+DE+7+DE+DEZEMBRO+DE+2004.pdf?MOD=AJPERES. Acesso em 18 de Outubro de 2014. 
BELTRAME, L. T. C. Caracterização de efluente têxtil e Proposta de tratamento, em Natal/RN [dissertação]. Natal: Universidade Federal do Rio Grande do Norte; 2000.

BEZERRA, F.F.N. A Gestão ambiental nas indústrias de confecção com lavanderia em Teresina, em Teresina/PI [disseração]. Universidade Federal do Piauí; 2006. 102p.

BEZERRA, F. F. N.; MONTEIRO, M.S.L.. Sistema de Gestão Ambiental ou Produção mais limpa? Estudo de caso nas Indústrias de Confecções com lavanderia, em Teresina/Piauí. REDE- Revista Eletrônica do Prodena, v. 3, n.1, p. 42-61, 2009.

BARROS, A. J. S.; LEHFELD, N. A. S. Fundamentos da metodologia de científica. 2.ed. São Paulo: Pearson Makron Books, 2000.

BRASIL. Ministério da Saúde. Portaria n ${ }^{\circ}$ 1.884/GM de 11.11.1994. Normas para projetos Físicos de Estabelecimentos Assistenciais de Saúde. Brasília, MS, 1994. Disponível em $<$ http://bvsms.saude.gov.br/bvs/publicacoes/normas_montar_centro_.pdf >. Acesso em: 18 de Outubro de 2014.

BRASIL. Lei no 9.433, de 8 de Janeiro de 1997. Institui a Política Nacional de Recursos Hídrico. Disponível em: < http://www.planalto.gov.br/CCIVIL_03/leis/L9433.htm>. Acesso em: 30 de Out. de 2014.

BRASIL. Lei no 357, de 17 de Março de 2005. Dispõe sobre a classificação dos corpos de água e diretrizes ambientais. Acesso em: < http://www.mma.gov.br/port/conama/res/res05/res35705.pdf>. Acesso em: 04 de nov. de 2014.

BRASIL. Lei no 430, de 13 de Maio de 2011. Completa e altera a Resolução no 357/2005. Disponível em: < http://www.mma.gov.br/port/conama/legiabre.cfm?codlegi=646>. Acesso em: 04 de nov. de 2014.

BRUNO, F. S; BRUNO, A. C. M. O papel do setor têxtil e de confecção brasileiro na liderança de um modelo sustentável de desenvolvimento. Revista Produção Online, v. 9, n. 2, p. 551-571. 2009.

BJØRN, A.; HAUSCHILD, M. Z. Absolute versus Relative Environmental Sustainability. Journal of Industrial Ecology, v. 1, n. 2, p. 321-332, 2013.

CARGNIN, M. T. Análise do processo de lavagem e desinfecção de roupas hospitalares: o caso da

lavanderia HUSM, em Santa Maria/RS [Dissertação]. Santa Maria: Universidade Federal de Santa Maria; 2008. 153p.

CETESB - Companhia de Tecnologia de Saneamento Ambiental. Resíduos Sólidos. Disponívem em: http://sistemasinter.cetesb.sp.gov.br/Ar/php/mapa_qualidade_rmsp.php. Acesso em: 27 de Outubro de 2014.

CHEN, Z.; NGO, H. H. ; GUO, W. A critical review on sustainability assessment of recycled water schemes. Science of the Total Environment, v. 426, p. 13-31. 2012.

CONCHON, J. A. Tratamento de Efluentes. Revista Base Textil, n. 123, 1999.

CONAMA - Conselho Nacional do Meio Ambiente. Condições e padrões de lançamento de efluentes. Disponível em < http://www.mma.gov.br/port/conama/legiabre.cfm?codlegi=646>. Acesso em: 24 de Outubro de 2014. 
CORSAN - Companhia Riograndense de Saneamento. Informações tarifárias. Disponível em: http://www3.corsan.com.br/informacoes/tabelas_estrutura_tarifaria.html. Acesso em: 07 de Abril de 2015 .

DMAE - Departamento Municipal de Água e Esgoto. Informações tarifárias. Disponível em: http://dmae.montecarmelo.mg.gov.br/contas/tarifas/. Acesso em: 04 de Abril de 2015.

DYLLICK, T.; HOCKERTS, K. BEYOND THE BUSINESS CASE FOR CORPORATE SUSTAINABILITY. Business Strategy and the Environment, v. 11, p. 130-141, 2002.

EHRENFELD, J. R. Industrial ecology: a framework and process design. Journal of Cleaner Production, v. 5, n. 1, p. 87-95. 1997.

FARIA, F. P.; PACHECO, E. B. A. V. Experiências com Produção Mais Limpa no Setor Têxtil. Revista de Design Inovação e Gestão Estratégica v. 2, n. 1, 2011.

FIRJAN. Manual de conservação e reúso da água na indústria. Rio de Janeiro: DIM, 2006.

FREITAS, K. R. Caracterização e Reuso de efluentes do processo de beneficiamento da Indústria Têxtil. [dissertação]. Florianópolis: Universidade Federal de Santa Catarina/UFSC; 2002. p. 130.

GARRIDO-BARSEBA, M. REIF, R. HERNANDEZ, F. PONCH, M. Implementation of a knowledgebased methodology in a decision support system for the design of suitable wastewater treatment process flow diagrams. Journal of Environmental Management, v. 112, p. 384-391. 2012.

GLADWIN T, KENNELLY J, KRAUSE T. Shifting paradigms for sustainable development: implications for management theory and research. Academy of Management Review, v. 20, n. 4, p. 874-907. 1995.

GORINI, A. P. F. Panorama do Setor Têxtil no Brasil e no Mundo: Reestruturação e Perspectivas. Banco Nacional de Desenvolvimento Econômico e Social Setorial, Rio de Janeiro, n. 12, p. 17 - 50, 2000 .

GIL, A. C. Como elaborar projetos de pesquisa. 5 ed. São Paulo: Atlas, 2010.

HERNÁNDEZ-SANCHO, F.; SALA-GARRIDO, R. Technical efficiency and cost analysis in wastewater treatment processes: a DEA approach, Desalination, v. 249, n. 1, pp. 230 234, 2009.

HUESEMANN, M. H. The failure of eco-efficiency to guarantee sustainability:Future challenges for industrial ecology. Environmental Progress, v. 23, n. 4, p. 264-270. 2004.

ITABORAHY, M.A.; SILVA, V.H. Indústrias de confecção no município de Cianorte-PR e a necessidade de implantação de programas de Gestão Ambiental. Revista Ciências Empresariais, v.12, n. 1, p.360-387, 2006.

JERÔNIMO, T.B.; GALVÃO M.B.; FALCÃO, J.M.S.L. Proposta de utilização do environment to businesses em projetos de recursos hídricos de despejo de produtos químicos: estudo de caso das lavanderias no munícipio de Toritama. Revista Eletrônica Serviços e Gestão, v. 7, p. 366-378. 2012.

MALHOTRA, N.K. Pesquisa de marketing: uma orientação aplicada. 6.ed. Porto Alegre: Bookman, 2012.

MEDEIROS, J. B. Redação Cientifica: a prática de fichamentos, resumos, resenhas. 11. ed. São Paulo: Atlas, 2011. 
MIGUEL, P. A.C et al. Metodologia de Pesquisa em engenharia de produção e gestão de operações. 2.ed. Rio de Janeiro: Elsevier: ABEPRO, 2012.

MINISTÉRIO DA SAÚDE. Manual de lavanderia hospitalar. Brasília: Ministério da Saúde, 1986.

NASCIMENTO, S. M. B. Gerenciamento do serviço de lavanderia no hospital universitário de londrina - HUL. [monografia]. Londrina: Departamento Pós-Graduação em Gestão Hospitalar e Serviço de Saúde/ UEL; 2011.

OLIVEIRA. M. M. Como fazer uma pesquisa qualitativa. 3 ed. Petrópolis, RJ: Vozes, 2010.

PACHER, B.A., VAZ, C.R., OLIVEIRA, I.L. Análise do gerenciamento de resíduos de lavanderias de Ponta Grossa. P\&D em Engenharia de Produção, v. 9, n. 2, p. 121-131, 2011.

PICCHIAI, D.; FARIAS.R.M. A visão sistêmica da Lavanderia Hospitalar: Limites e Propostas. Revista de Gestão em Sistemas de Saúde , v. 2, n. 2, p. 124-147. 2013.

RIBEIRO, F. M. A produção mais Limpa (P+L) no setor sucroalcooleiro - informações gerais. Câmara Ambiental do Setor Sucroalcooleiro GT de P+L: mudanças tecnológicas - procedimentos. São Paulo: CETESB, 2002.

SANIN, L. B. B. A indústria e o meio ambiente. Química Têxtil. Associação Brasileira de Químicos e Coloristas Têxteis, v. 46, p. 13-34, 1997.

SEBRAE - Serviço de apoio às médias e pequenas empresas. Disponível em: < http://www.sebrae.com.br/sites/PortalSebrae/ideias/Como-montar-uma-lavanderia-especializada> . Acesso em 27 de Outubro de 2014.

SILVA, E. L.; MENEZES, E. M. Metodologia da Pesquisa e elaboração da dissertação. 4ed. Florianópolis: UFSC, 2005.

SIQUEIRA, M. R. B. Qualidade e satisfação em serviços de lavanderia hospitalar terceirizada. [monografia]. Porto Alegre: Departamento de Administração/UFRGS; 2005.

SOMAVILLA, D. Proposta de Plano de gerenciamento de resíduos sólidos e Produção mais Limpa para uma indústria metalúrgica do município de Carazinho. [monografia]. Passo Fundo: Deparamento de Engenharia Ambiental/UPF; 2013.

UNEP - United Nations Environment Programme. Disponível em: $<$ http://www.uneptie.org/PC/cp/understanding_cp/home.htm>. Acesso em: 19 de Setembro de 2014.

VELLANI, C. L; RIBEIRO, M. S. Sistema Contábil para Gestão da Ecoeficiência Empresarial. Revista

Contabilidade \& Finanças. v. 20, n. 49, p. 25-43, 2009.

VERFAILLE H. A, BIDWELL R. Measuring Eco-Efficiency,a Guide to Reporting Company Performance. World Business Council for Sustainable Development: Geneva. 2000.

VON KROGH G, R. et al. Knowing in Firms: Understanding, Managing and Measuring Knowledge, 2nd edn. Sage: London. 1998.

YOUNES, S. B., ELLOUZE, M.; SAYADI, S. A comparative study of an industrial effluent treatment 
using enzymatic and alkaline adapted consortium assays. Journal of Chemical Technology Biotechnology, v. 88, p. 563-571. 2012.

WBCSD - World Business Council for Sustainable Development. Measuring eco-efficiency: a guide to reporting company performance. North Yorkshire, UK. 2000b.

WBCSD - World Business Council for Sustainable Development. Eco-efficiency: creating more value with less input. NorthYorkshire, UK. 2000a. 